\title{
Smart Card
}

National Cancer Institute

\section{Source}

National Cancer Institute. Smart Card. NCI Thesaurus. Code C19547.

Credit card-sized memory card that stores software applications and modem capabilities and that can be inserted in palmtop and laptop computers. 